\title{
Effect of total sleep deprivation on postprandial metabolic and insulin responses in shift workers and non-shift workers
}

\author{
Sophie M T Wehrens, Shelagh M Hampton, Rebecca E Finn and Debra J Skene \\ Centre for Chronobiology, Faculty of Health and Medical Sciences, University of Surrey, Guildford GU2 7XH, UK \\ (Correspondence should be addressed to S M T Wehrens; Email: sophie.wehrens@surrey.ac.uk or to D J Skene; Email: d.skene@surrey.ac.uk)
}

\begin{abstract}
Epidemiological studies have shown that shift workers are at a greater risk of developing cardiovascular disease which may, in part, be related to metabolic and hormonal changes. Partial sleep deprivation, a common consequence of rotating shift work, has been shown to affect glucose tolerance and insulin sensitivity. The current study investigated the effects of one night of total sleep deprivation, as a proxy for the first night shift, on postprandial glucose, insulin and lipid (triacylglycerols (TAGs) and non-esterified fatty acids (NEFAs)) responses under controlled laboratory conditions in shift workers and non-shift workers. Eleven experienced shift workers $(35 \cdot 7 \pm 7 \cdot 2$ years, mean \pm s.D. $)$ who had worked in shifts for $8 \cdot 7 \pm 5 \cdot 25$ years were matched with 13 non-shift workers who had worked for $32 \cdot 8 \pm 6 \cdot 4$ years. After an adaptation night and a baseline sleep night, volunteers were kept awake for $30 \cdot 5 \mathrm{~h}$, followed by a nap $(4 \mathrm{~h})$ and recovery
\end{abstract}

sleep. Blood samples were taken prior to and after a standard breakfast following baseline sleep, total sleep deprivation and recovery sleep. Basal TAG levels prior to the standard breakfast were significantly lower after sleep deprivation, indicating higher energy expenditure. Basal NEFA levels were significantly lower after recovery sleep. Postprandial insulin and TAG responses were significantly increased, and the NEFA response was decreased after recovery sleep, suggestive of insulin insensitivity. Although there were no overall significant differences between non-shift workers and shift workers, non-shift workers showed significantly higher basal insulin levels, lower basal NEFA levels, and an increased postprandial insulin and a decreased NEFA response after recovery sleep. In future, the reasons for these inter-group differences are to be investigated.

Journal of Endocrinology (2010) 206, 205-215

\section{Introduction}

Epidemiological studies have shown that shift workers may be at a higher risk of developing cardiovascular disease (CVD; e.g. Kawachi et al. 1995, Boggild \& Knutsson 1999, Karlsson et al. 2001, 2003, Ellingsen et al. 2007, Sookoian et al. 2007, De Bacquer et al. 2009, Esquirol et al. 2009). The mechanisms underlying this phenomenon are still unclear, but the increased risk may, in part, be related to circadian misalignment (Knutsson \& Boggild 2000). The circadian clock plays an important role in the regulation of endogenous metabolic processes (Woon et al. 2007, Green et al. 2008, Monteleone et al. 2008, Scott et al. 2008, Sookoian et al. 2008). Under entrained or adapted circumstances, these endogenous processes are synchronised to or in phase with daily routines, such as food intake and sleep. However, shift work studies done by our group (Hampton et al. 1996, Ribeiro et al. 1998, Lund et al. 2001) and by other groups (Simon et al. 2000, Scheer et al. 2009) have shown altered hormone and metabolic responses when subjects were phase shifted (i.e. intake of food at a different circadian clock time). In addition to circadian misalignment, sleep deprivation commonly occurs during rotating shift work or permanent

night work (e.g. Akerstedt 1998, Pilcher et al. 2000, Sallinen et al. 2003). Epidemiological research has shown that sleep deprivation is associated with obesity, hypertension, and metabolic and hormonal changes associated with CVD (e.g. Taheri et al. 2004, Gangwisch et al. 2006). In agreement with these reports, laboratory studies have demonstrated decreased glucose tolerance and insulin sensitivity after partial sleep deprivation, restricting sleep to either $5.5 \mathrm{~h}$ for 14 nights or $4 \mathrm{~h}$ for 6 nights (Spiegel et al. 1999, Nedeltcheva et al. 2009), and a significant reduction in the triacylglycerol (TAG) rhythm amplitude and average TAG levels after 3-5 days of total sleep deprivation (Vondra et al. 1986).

Furthermore, it is likely that there are inter-individual differences in the vulnerability to the effects of shift work and sleep deprivation, due to, for example, diurnal preference (morningness-eveningness; Taillard et al. 1999, Mongrain et al. 2006), genetics (Retey et al. 2006, Viola et al. 2007, 2008) or shift work history. Epidemiological studies, however, do not always detail the shift work duration, so it is difficult to assess the relationship between shift work duration and adverse health effects. The shift work duration beyond which health effects are measurable may range from more than 6 to 10 years (Kawachi et al. 1995, De Bacquer et al. 2009, 
Esquirol et al. 2009) to as short as 1-2 years (Knutsson et al. 1986, Schernhammer et al. 2001). Long-term shift work may lead to either adaptation or sensitisation to the effects of sleep deprivation. This suggests that non-shift workers and experienced shift workers may respond differently when subjected to the same sleep restriction conditions and dietary intake.

The effect of one night of total sleep deprivation on basal glucose and insulin levels and the postprandial response to a standard breakfast have not been investigated yet, even though total sleep deprivation is similar to the first night shift for many shift workers (e.g. Pilcher et al. 2000, Akerstedt 2003, Sallinen et al. 2003). A nap is often taken after this night shift, although this occurence and length of sleep and nap periods appears to be highly dependent on the shift work pattern and other circumstances, such as family commitments (Pilcher et al. 2000, Akerstedt 2003, Sallinen et al. 2003). In addition, the effects of shift work experience have not been assessed when food is given at a normal circadian clock time (i.e. similar to what occurs in non-shift workers). Finally, shift workers and matched non-shift workers have not been compared simultaneously under controlled laboratory conditions.

The aim of the current study was to investigate the effect of one night of total sleep deprivation per se compared to baseline sleep and recovery sleep on basal and postprandial metabolic and insulin responses following a standard breakfast under controlled laboratory conditions. In addition, the responses of experienced shift workers (with a shift work duration of 5 years or more) were compared with those of non-shift workers.

\section{Materials and Methods}

\section{Procedures}

The University of Surrey Ethics Committee gave a favourable opinion for all the aspects of this study. All volunteer information was kept coded and held in strictest confidence in compliance with the Data Protection Act (1998). Male shift workers and non-shift workers between 25 and 45 years of age were recruited. All the participants gave written informed consent. Written consent was also obtained from the subject's general practitioner confirming the subject's suitability to participate in the study.

Pre-study screening and the laboratory part of the study took place in the Clinical Investigation Unit (CIU) of the Faculty of Health and Medical Sciences at the University of Surrey.

\section{Screening and subjects}

An extensive screening procedure was applied. Shift workers were required to have a recent cumulative shift work history of 5 years or more (preferably continuous), working either permanent night or rotating shifts with at least three night shifts per month. Non-shift workers were required to have a cumulative shift work history of $<6$ months over their life time. Waist and hip circumferences were measured, and a general health questionnaire and four validated questionnaires were completed: Horne-Östberg questionnaire (HÖ; Horne \& Östberg 1976), Pittsburgh Sleep Quality Index (PSQI; Buysse et al. 1989), Beck's depression inventory (BDI; Beck \& Beamesderfer 1974, Beck et al. 1974) and Epworth Sleepiness Scale (ESS; Johns 1991, 1992). As PSQI, BDI and ESS were dependent on the current shift pattern of shift workers, second assessments were carried out for some of the subjects during the week prior to the study or before the adaptation night. These shift workers were asked to keep only days off or day shifts in mind when completing the questionnaires. Shift workers were also asked to complete the Standard Shift work Index (Barton et al. 1995), which was used to determine the total shift work duration and the shift pattern of their last job. Subjects were free of any medical conditions and medication, including over-the-counter medication, thought to affect cardiovascular, metabolic, gastrointestinal and immune functions. In addition, they had normal results for the haematological and biochemical screening, did not smoke, did not consume more than 15 units of alcohol a week and were negative for drugs of abuse at the time of recruitment and during the study. Demographics of the 24 participants (13 non-shift workers and 11 shift workers) are given in Table 1.

\section{Prior to the laboratory session}

In order to maintain or establish regular circadian rhythms (i.e. for the shift workers to be adapted for the laboratory study) and to minimise sleep debt, volunteers were asked to maintain a self-selected regular sleep-wake cycle with a sleep duration of $7 \cdot 5$ or $8 \mathrm{~h}$ for 8 days prior to the laboratory study (bed time $23.3 \pm 0.5 \mathrm{~h}$ (mean \pm s.D.), range $22-24 \mathrm{~h}$, wake up time $7 \cdot 2 \pm 0 \cdot 5 \mathrm{~h}, 5 \cdot 5-8 \mathrm{~h}$, and sleep duration $7 \cdot 9 \pm 0 \cdot 2 \mathrm{~h}$, $7 \cdot 5-8 \mathrm{~h}$ ). Volunteers were allowed to nap within a $4-\mathrm{h}$ window in the afternoon (centred $12 \mathrm{~h}$ away from the midpoint of their nighttime sleep to avoid phase shifting of circadian rhythms (Buxton et al. 2000)). To confirm their regular sleep-wake cycle, the participants were asked to call the laboratory's voicemail within $10 \mathrm{~min}$ before going to bed and after waking up, to wear two actiwatches (Actiwatch-L (AWL); Cambridge Neurotechnology, Cambridge, UK), one around their neck and another on their non-dominant wrist, both recording activity and light exposure, and to complete a daily sleep diary (Lockley et al. 1999). For the 7 days prior to and on the morning of the laboratory study, the study participants were asked to get $15 \mathrm{~min}$ exposure to outdoor natural light (without wearing sunglasses) within $90 \mathrm{~min}$ after waking up to strengthen the regularity of their circadian rhythms (Revell et al. 2005).

Two days prior to the laboratory study, the participants were asked to refrain from alcohol, caffeine and heavy exercise. 
Table 1 Characteristics of the non-shift workers and shift workers during the first assessment. Values are means \pm s.D. and ranges (between brackets), measured on the screening day or the baseline day of the laboratory study for basal levels of glucose, TAGs, NEFAs and insulin

\begin{tabular}{|c|c|c|}
\hline & Non-shift workers $(n=13)$ & Shift workers $(n=11)$ \\
\hline Shift work (years) & $0 \cdot 03 \pm 0 \cdot 12(0-0 \cdot 42)$ & $8 \cdot 7 \pm 5 \cdot 2^{* * *}(5-18 \cdot 5)$ \\
\hline Time since last shift (months) & 60 & $1 \cdot 6 \pm 5 \cdot 4(0-18)$ \\
\hline Age (years) & $32 \cdot 8 \pm 6 \cdot 4(25-42)$ & $35 \cdot 7 \pm 7 \cdot 2(25-45)$ \\
\hline Weight (kg) & $84 \cdot 6 \pm 13 \cdot 6(67 \cdot 8-109)$ & $91 \cdot 6 \pm 10 \cdot 3(82-117)$ \\
\hline Height $(\mathrm{m})$ & $1 \cdot 77 \pm 0.06(1.66-1 \cdot 85)$ & $1.79 \pm 0.07(1.71-1.91)$ \\
\hline BMI $\left(\mathrm{kg} / \mathrm{m}^{2}\right)$ & $26 \cdot 8 \pm 3 \cdot 5(21 \cdot 5-34 \cdot 0)$ & $28 \cdot 7 \pm 3 \cdot 8(23-35 \cdot 7)$ \\
\hline Waist circumference $(\mathrm{cm})$ & $92 \pm \overline{9} \cdot 3(76-107)$ & $98 \pm \overline{6} \cdot 7(90-110)$ \\
\hline Hip circumference $(\mathrm{cm})$ & $101 \pm 7 \cdot 6(88-114)$ & $106 \pm 6 \cdot 2(95-114)$ \\
\hline WHR & $0.91 \pm 0.03(0.86-0.96)$ & $0.93 \pm 0.03(0.86-0.98)$ \\
\hline Cholesterol (mmol/l) & $4 \cdot 8 \pm 0 \cdot 5(3 \cdot 9-5 \cdot 5)$ & $4 \cdot 9 \pm 1 \cdot 1(3-6 \cdot 5)$ \\
\hline $\mathrm{HDL}(\mathrm{mmol} / \mathrm{l})$ & $1 \cdot 3 \pm 0 \cdot 2(0 \cdot 8-1 \cdot 6)$ & $1 \cdot 4 \pm 0 \cdot 4(0 \cdot 9-2 \cdot 4)$ \\
\hline Glucose (mmol/l) & $5 \cdot 1 \pm 0 \cdot 4(4 \cdot 4-5 \cdot 9)$ & $5 \cdot 2 \pm 0 \cdot 2(4 \cdot 8-5 \cdot 6)$ \\
\hline TAGs $(\mathrm{mmol} / \mathrm{l})$ & $1 \cdot 4 \pm 0 \cdot 4(0 \cdot 7-2 \cdot 1)$ & $1 \cdot 3 \pm 0 \cdot 5(0 \cdot 9-2 \cdot 5)$ \\
\hline NEFAs $(\mathrm{mmol} / \mathrm{l})$ & $0 \cdot 3 \pm 0 \cdot 1(0 \cdot 2-0 \cdot 6)$ & $0 \cdot 3 \pm 0 \cdot 1(0 \cdot 2-0 \cdot 5)$ \\
\hline Insulin $(\mathrm{pmol} / \mathrm{l})$ & $67 \cdot 5 \pm 12 \cdot 4(47 \cdot 3-81 \cdot 7)$ & $63 \pm 16 \cdot 8(38 \cdot 3-92 \cdot 2)$ \\
\hline Smoke currently (units/day) & $0-12.100$ & 0 \\
\hline Smoked in the past (units/day) & $3 \cdot 9 \pm 5 \cdot 9(0-15 \cdot 5)$ & $4 \cdot 5 \pm 5 \cdot 7(0-15)$ \\
\hline Smoking duration (years) & $2 \cdot 9 \pm 4 \cdot 5(0-14)$ & $4 \cdot 4 \pm 6 \cdot 3(0-20)$ \\
\hline Time since last smoked (months) & $17 \cdot 9 \pm 24 \cdot 1(0 \cdot 5-60)$ & $38 \cdot 4 \pm 54 \cdot 1(0 \cdot 25-132)$ \\
\hline $\mathrm{HÖ}$ & $59 \cdot 3 \pm 5 \cdot 2(51-70)$ & $55 \cdot 5 \pm 13 \cdot 0(34-75)$ \\
\hline $\mathrm{PSQI}^{\mathrm{a}}$ & $4 \cdot 0 \pm 1 \cdot 9(1-7)$ & $5 \cdot 1 \pm 2 \cdot 2(2-10)$ \\
\hline $\mathrm{BDI}^{\mathrm{a}}$ & $3 \cdot 3 \pm 3 \cdot 1(0-9)$ & $4 \cdot 7 \pm 4 \cdot 9(0-17)$ \\
\hline $\mathrm{ESS}^{\mathrm{a}}$ & $4 \cdot 7 \pm 3 \cdot 3(1-11)$ & $6 \cdot 2 \pm 3 \cdot 3(2-11)$ \\
\hline
\end{tabular}

${ }^{* * *} P<0 \cdot 001$ compared with non-shift workers by independent two-tailed $t$-test. BMI, body mass index; WHR, waist-hip ratio; $\mathrm{HDL}$, high-density lipoprotein; TAGs, triacylglycerols; NEFAs, non-esterified fatty acids; HÖ, Horne-Östberg questionnaire; PSQI, Pittsburgh Sleep Quality Index; BDI, Beck's depression inventory; ESS, Epworth Sleepiness Scale.

a Values given are those obtained during the week prior to the study (see Materials and Methods).

On the day the subjects came to the laboratory they were asked to refrain from foods and drinks other than water for $6 \mathrm{~h}$ before the standard dinner provided in the CIU.

\section{The laboratory session}

Volunteers spent four nights and days in the CIU (Fig. 1). Light was kept constant at $<8$ lux in the direction of gaze (apart from darkness (0 lux) during the sleep periods). Light levels were regularly checked with a calibrated lux meter (Edmund Optics, York, UK). Temperature was set around $20^{\circ} \mathrm{C}$, and both light and temperature in the CIU were continuously recorded with Hobo sensors (Tempcon, Arundel, UK).

After an adaptation night and a baseline night, the subjects were required to stay awake for $30 \cdot 5 \mathrm{~h}$, followed by a $4-\mathrm{h}$ recovery nap and a recovery sleep (bed and wake up times for the three nights in the CIU were equal to those of the week prior to the study). The subjects were continually monitored during the hours they were supposed to be awake by the staff in order to ensure that they did not fall asleep (which was evaluated post hoc with polysomnography). In order to control for inter-individual differences in circadian phase, all interventions and measurements were scheduled relative to each subject's self-selected wake up time (Burgess et al. 2003).

Body posture was controlled throughout the study. Subjects were asked to remain in a semi-recumbent position in bed during the sleep and sleep-deprivation periods and for $4 \mathrm{~h}$ each afternoon. Blood sampling was performed in a seated position. Subjects were allowed to use the toilet during these periods, but were instructed to be seated $20 \mathrm{~min}$ before the collection of each blood sample.

\section{Food intake}

All the subjects were provided with the same standard breakfast, lunch, dinner and evening snack throughout the study at $1 \cdot 75,4 \cdot 75,12$ and $15 \mathrm{~h}$ after wake up time (Table 2). Between these meals, the subjects were not allowed to have any food or drinks except water made available ad libitum. The breakfast had a relatively high fat and sugar content in order to elicit a well-defined postprandial response. The snack was included in the protocol to reduce the feelings of hunger and irritation during sleep deprivation.

\section{Blood sampling}

On the baseline day, a cannula was inserted by a qualified nurse. After baseline sleep, sleep deprivation and recovery sleep, blood samples were taken 15 and 0 min prior to and 15 , $30,45,60,90,120,180$ and $240 \mathrm{~min}$ after the standard breakfast. The first sample of the day was taken $1.5 \mathrm{~h}$ after wake up time, following a $10 \cdot 5-\mathrm{h}$ fast. 


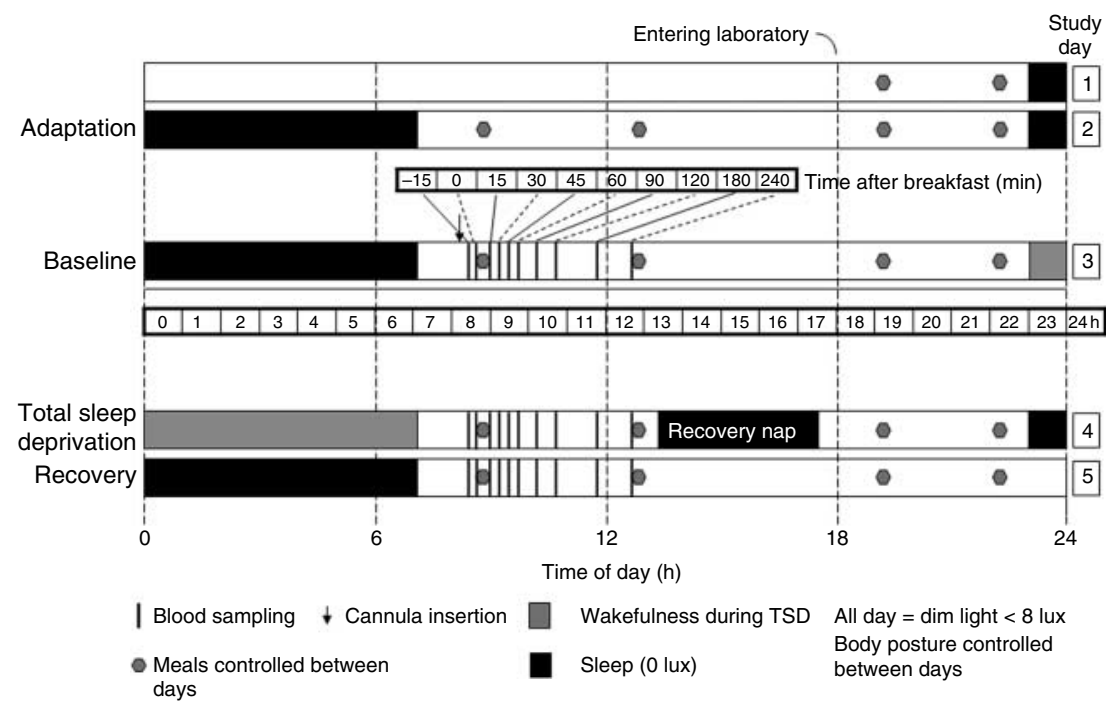

Figure 1 Laboratory protocol followed during the five study days for a subject sleeping from 2300 to $0700 \mathrm{~h}$. All interventions (see key) were relative to the subject's self-selected wake up time.

\section{Assay procedures}

Plasma was separated by centrifugation at $1750 \mathrm{~g}, 4^{\circ} \mathrm{C}$ for $10 \mathrm{~min}$, aliquoted and stored at $-20^{\circ} \mathrm{C}$ until analysis. Metabolite levels were determined with the Ilab 650 (Instrumentation Laboratory, Warrington, UK) using reagents for the enzymatic colorimetric detection of glucose, TAGs (IL TestTM, Instrumentation Laboratory) and nonesterified fatty acid (NEFAs; Randox Laboratories Ltd, Crumlin, UK). Inter-assay coefficients of variation (CV) were $<5 \%$ for glucose and TAGs, and $<10 \%$ for NEFAs.

Plasma insulin was measured using a human insulin-specific RIA kit (Millipore Ltd, Watford, UK). The plasma was thawed and centrifuged at $1500 \mathrm{~g}$ for $5 \mathrm{~min}$ at $4{ }^{\circ} \mathrm{C}$. All the samples from one shift worker and one non-shift worker were measured in the same assay, and the day order was randomised to minimise any effects of possible assay drift. The inter-assay $\mathrm{CV}$ was $<15 \%$. One non-shift worker had an extremely high insulin response ( $>2$ s.D. from the mean), was considered an outlier and was excluded from all the insulin analyses.

\section{Statistical analysis}

An independent two-tailed Student's $t$-test was used to compare the demographics of the non-shift workers and shift workers and the basal TAG, NEFA, glucose and insulin levels on the baseline day of the study. For the ANOVAs, some missing values were compiled by linear intra-/extrapolation $(<4 \%$ of the data set). The effects of baseline sleep, total sleep deprivation and recovery sleep on the time course of TAGs, NEFAs, glucose and insulin in the non-shift workers and shift workers were compared using a three-factor ANOVA (factors 'day' (three levels: 'baseline sleep', 'total sleep deprivation' and 'recovery sleep'), 'time' (ten levels: time points $15 \mathrm{~min}$ prior to $240 \mathrm{~min}$ after the standard meal) and 'group' (two levels: 'non-shift workers' and 'shift workers')). If applicable, the $P$ values for the effects in all ANOVAs were Greenhouse-Geisser adjusted when Mauchly's test for sphericity was significant. Tukey's honest significant difference post hoc tests were used to locate significant differences after a significant main effect or interaction. Whether postprandial levels returned to basal levels (the mean of the -15 and 0 time points) was assessed using a threefactor ANOVA (factors 'day', 'time' (two levels: 'basal state' and '240 min') and 'group'). Basal levels and incremental area under the curve (IAUC; total area under the curve minus the area under the basal level) were analysed using a two-factor ANOVA (factors 'day' and 'group'). For NEFAs, many data points were lower than the basal level, so a net IAUC was calculated as the area above the basal level minus the area below the basal level. Since statistically significant differences between the groups may not be revealed in these combined analyses due to the small sample number, non-shift workers and shift workers were also analysed separately using ANOVA.

Table 2 Percentage of fat, protein and carbohydrates and energy for each of the meals and overall composition of all the meals

\begin{tabular}{|c|c|c|c|c|}
\hline & $\begin{array}{l}\text { Protein } \\
(\%)\end{array}$ & $\begin{array}{l}\text { Fat } \\
(\%)\end{array}$ & $\begin{array}{l}\text { Carbohydrate } \\
(\%)\end{array}$ & $\begin{array}{l}\text { Energy } \\
\text { (kcal) }\end{array}$ \\
\hline Breakfast & $7 \cdot 8$ & $39 \cdot 7$ & $53 \cdot 3$ & $967 \cdot 5$ \\
\hline Lunch & $14 \cdot 1$ & $53 \cdot 6$ & $32 \cdot 2$ & $996 \cdot 9$ \\
\hline Dinner & $13 \cdot 3$ & $43 \cdot 9$ & $42 \cdot 5$ & $950 \cdot 0$ \\
\hline Evening snack & $14 \cdot 9$ & $25 \cdot 4$ & $59 \cdot 1$ & $300 \cdot 0$ \\
\hline $\begin{array}{l}\text { Overall } \\
\text { composition }\end{array}$ & $12 \cdot 0$ & 43.9 & $44 \cdot 1$ & $3214 \cdot 4$ \\
\hline
\end{tabular}




\section{Results}

Comparison of shift workers and non-shift workers

The characteristics of the participants are given in Table 1. Basal plasma glucose, TAG, NEFA and insulin levels measured on the baseline day of the laboratory study and other parameters determined on the screening day were not significantly different between shift workers and non-shift workers, apart from, as expected, the number of years the subjects had worked in shifts $(P<0 \cdot 001)$.

ANOVAs showed that the 'group' effect (shift workers versus non-shift workers) was not significant in any of the analyses described hereafter.

\section{Basal levels}

Basal levels of plasma TAGs, NEFAs, insulin and glucose after baseline sleep, sleep deprivation and recovery sleep are shown in Fig. 2. There was a significant effect of day on basal TAG levels $\left(F_{2,44}=13 \cdot 7, P<0 \cdot 001\right)$, with significantly lower TAG levels after total sleep deprivation $(1 \cdot 2 \pm 0 \cdot 1 \mathrm{mmol} / \mathrm{l}$ (mean \pm S.E.M. $))$ than after baseline $(1 \cdot 3 \pm 0 \cdot 1 \mathrm{mmol} / \mathrm{l})$ and recovery $(1.5 \pm 0.1 \mathrm{mmol} / \mathrm{l})$ sleep $(P<0.05$ and $P<0.001$ respectively). When analysing the subject groups separately, both the non-shift workers and shift workers showed significant effects of day $\left(F_{2,24}=11 \cdot 1, P<0 \cdot 001 ; F_{2,20}=4 \cdot 4, P<0.05\right.$ respectively), with a larger increase in basal TAGs after recovery sleep than after sleep deprivation in the non-shift workers $(P<0 \cdot 001)$ than in the shift workers $(P<0 \cdot 05)$. There was a similar significant effect of day on basal glucose levels $\left(F_{2,44}=3 \cdot 3, P<0 \cdot 05\right)$ with lower basal glucose levels after total sleep deprivation $(5 \cdot 1 \pm 0 \cdot 0 \mathrm{mmol} / \mathrm{l})$ than after baseline $(5 \cdot 2 \pm 0 \cdot 1 \mathrm{mmol} / \mathrm{l})$ and recovery $(5 \cdot 2 \pm 0 \cdot 1 \mathrm{mmol} / \mathrm{l})$ sleep; however, Tukey's post hoc test was not significant.

In the combined data set, there was a significant effect of day on basal NEFA levels $\left(F_{2,44}=4 \cdot 2, P<0 \cdot 05\right)$, with significantly lower NEFA levels after recovery sleep $(0 \cdot 25 \pm 0 \cdot 01 \mathrm{mmol} / \mathrm{l})$ than after baseline sleep $(0.31 \pm 0.02 \mathrm{mmol} / \mathrm{l} ; P<0 \cdot 05)$. When the subject groups were analysed separately, this appeared to be mainly due to a significant effect of day in the non-shift workers $\left(F_{2,24}=6 \cdot 4, P<0 \cdot 01\right)$, with lower NEFA levels after recovery sleep $(0.25 \pm 0.02 \mathrm{mmol} / \mathrm{l})$ than after baseline sleep $(0 \cdot 34 \pm 0 \cdot 04 \mathrm{mmol} / 1 ; P<0 \cdot 01)$. A significant day $\times$ group interaction was observed for basal insulin levels $\left(F_{2,42}=4 \cdot 2, P<0 \cdot 05\right)$, revealing higher basal insulin levels after recovery sleep $(86 \cdot 0 \pm 8 \cdot 1 \mathrm{pmol} / \mathrm{l})$ than after baseline sleep $(67 \cdot 4 \pm 3 \cdot 6 \mathrm{pmol} / \mathrm{l} ; P<0 \cdot 01)$ and sleep deprivation $(70 \cdot 0 \pm 5 \cdot 4 \mathrm{pmol} / 1 ; P<0 \cdot 05)$ in the non-shift workers.

\section{Postprandial responses}

Raw data The time courses for TAGs, NEFAs, insulin and glucose were assessed after baseline sleep, sleep deprivation and recovery sleep. The graphs of the raw data for non-shift workers, shift workers and all the subjects are shown in Fig. 3.

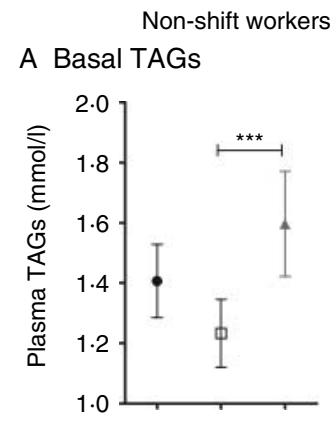

Shift workers

All subjects

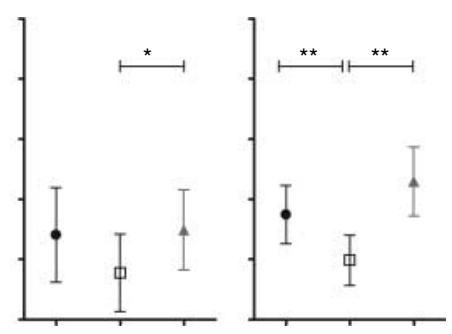

\section{B Basal NEFAs}
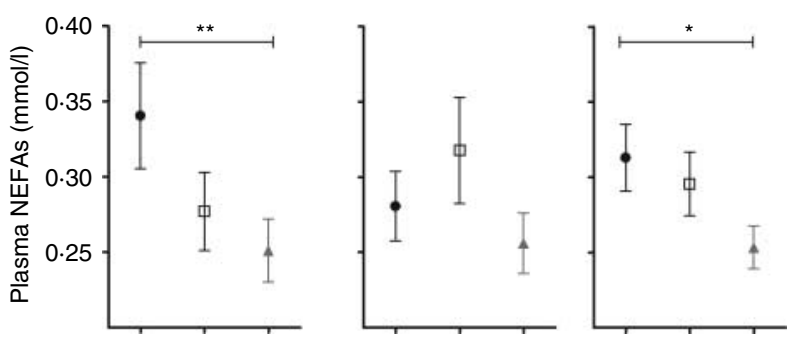

C Basal insulin

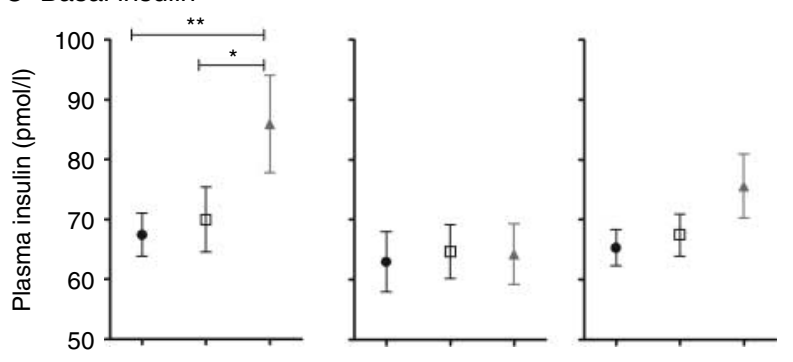

D Basal glucose

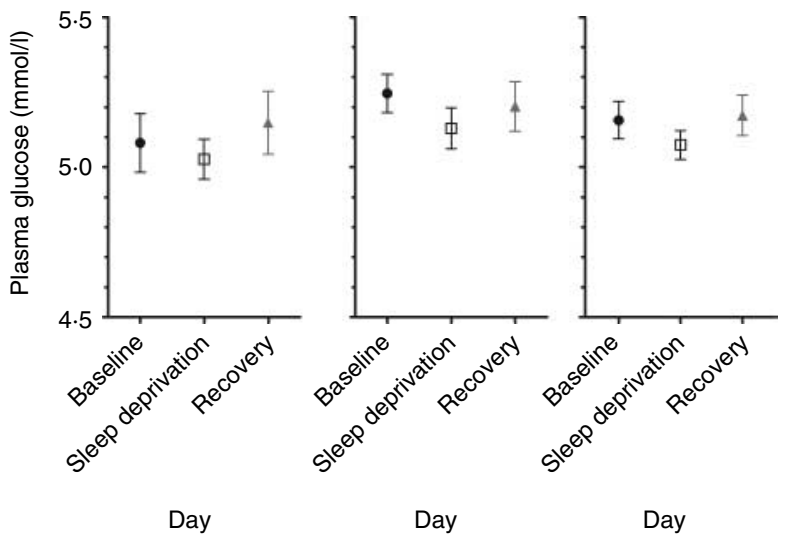

Figure 2 Basal plasma (A) TAGs, (B) NEFAs, (C) insulin and (D) glucose (mean \pm s.E.M.) following baseline sleep (•), sleep deprivation $(\square)$ and recovery sleep $(\Lambda)$ in the non-shift workers, shift workers and all the subjects. ${ }^{*} P<0 \cdot 05,{ }^{*} P<0 \cdot 01$ and $* * * P<0 \cdot 001 . n=13$ for non-shift workers ( $n=12$ for insulin) and $n=11$ for shift workers. Basal levels $=$ mean of -15 and 0 time points. 


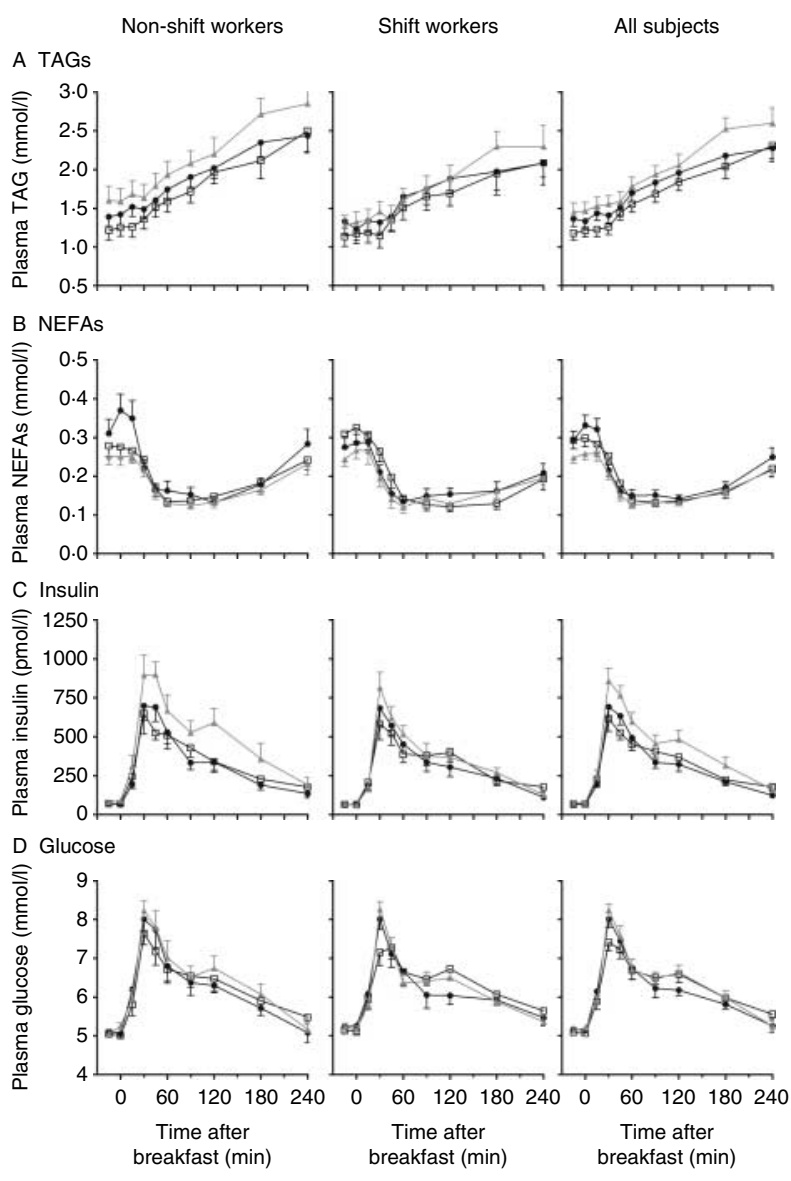

Figure 3 Plasma (A) TAGs, (B) NEFAs, (C) insulin and (D) glucose (mean \pm S.E.M.) prior to $(-15$ and $0 \mathrm{~min})$ and after (15-240 $\mathrm{min}) \mathrm{a}$ standard breakfast, following baseline sleep (•), sleep deprivation $(\square)$ and recovery sleep $(\Delta)$ in the non-shift workers, shift workers and all the subjects. $n=13$ for non-shift workers ( $n=12$ for insulin) and $n=11$ for shift workers.

There was a significant effect of day on TAG levels $\left(F_{2,44}=\right.$ $10 \cdot 9, P<0 \cdot 001)$, with TAGs being significantly increased after recovery sleep than after total sleep deprivation $(P<0 \cdot 001)$ and baseline sleep $(P<0 \cdot 05)$. When non-shift workers and shift workers were analysed separately, both the groups showed a significant effect of day, but the effect was stronger in the non-shift workers $\left(F_{2,24}=8 \cdot 2, P<0 \cdot 01\right)$ than in the shift workers $\left(F_{2,20}=3 \cdot 7, P<0 \cdot 05\right)$. Insulin showed a significant day $\times$ group interaction $\left(F_{2,42}=4 \cdot 2, \quad P<0 \cdot 05\right)$, with higher levels after recovery sleep than after total sleep deprivation and baseline sleep in the non-shift workers $(P<0 \cdot 001)$. When non-shift workers and shift workers were analysed separately, both the groups showed a significant effect of day, but the effect was stronger in the non-shift workers $\left(F_{2,22}=10 \cdot 9, P<0 \cdot 001\right)$ than in the shift workers $\left(F_{2,20}=4 \cdot 3\right.$, $P<0 \cdot 05)$. Post hoc tests showed that insulin levels were significantly higher after recovery sleep than after total sleep deprivation and baseline sleep in the non-shift workers $(P<0 \cdot 01)$, and that they were significantly higher than those after sleep deprivation in the shift workers $(P<0 \cdot 05)$. A significant effect of day was also observed for NEFAs $\left(F_{2,44}=5 \cdot 2, P<0 \cdot 01\right)$, with lower NEFA levels after recovery sleep than after baseline sleep $(P<0 \cdot 01)$. When the groups were analysed separately, the NEFA levels after recovery sleep were significantly lower than those after baseline sleep in the non-shift workers only $(P<0 \cdot 01)$. For glucose, no significant effect of day was observed, but there was a significant interaction between day and time $\left(F_{8 \cdot 3,183 \cdot 2}=2 \cdot 2, P<0 \cdot 05\right)$, indicating that the time course of the glucose response varied over the 3 days. The post hoc tests revealed that the only difference between the same time points on different days was an elevated glucose level $30 \mathrm{~min}$ after the standard breakfast following recovery sleep, compared with that after total sleep deprivation $(P<0 \cdot 05)$. Separate analyses of the groups did not show any significant effects of day or day $\times$ time interactions.

Normalised data Since there was a statistically significant effect of day on basal TAG, NEFA, insulin and glucose levels (Fig. 2), the postprandial responses were also analysed as a percentage of the basal levels. Using normalised data, no statistically significant effects were found, apart from a day $\times$ time interaction for glucose $\left(F_{16,352}=2 \cdot 0, P<0 \cdot 05\right)$. However, in contrast to the raw data, there were no significant differences between the same time points on different days.

\section{Return to basal levels}

To assess the postprandial return to basal levels, the levels prior to the standard breakfast were compared to the levels $4 \mathrm{~h}$ after the breakfast (240 min time point) across the 3 days. Statistical analyses showed a significant day $\times$ time interaction $\left(F_{2,44}=3.9, P<0.05\right)$ for glucose in the combined subject group, revealing that glucose levels after the standard breakfast did not return to basal levels by $240 \mathrm{~min}$ after total sleep deprivation $(P<0 \cdot 01$; Fig. $4 \mathrm{~B}$ a). Insulin in the combined subject group also showed a day $X$ time interaction $\left(F_{2,42}=4 \cdot 2, P<0 \cdot 05\right)$, with higher insulin levels $240 \mathrm{~min}$ after the standard breakfast following total sleep deprivation compared with those following baseline sleep $(P<0 \cdot 01$; Fig. 4A b). In addition, insulin levels were significantly higher $240 \mathrm{~min}$ after the standard breakfast than before the breakfast on all of the 3 days in each of the subject groups and the combined data set (Fig. 4A c). Similarly, TAGs and NEFAs showed significant effects of time in each of the subject groups and the combined data set, indicating that the levels $240 \mathrm{~min}$ after the standard breakfast did not return to basal levels on any of the 3 days, apart from those of NEFAs in the non-shift workers (data not shown).

\section{Incremental area under the curve}

IAUCs for TAGs, NEFAs, insulin and glucose were calculated, and are shown in Fig. 5. Analysis of the IAUCs showed a significant effect of day on the insulin $\left(F_{1 \cdot 4,30 \cdot 4}=\right.$ $9 \cdot 7, \quad P<0 \cdot 01)$ response in the combined subject group. 

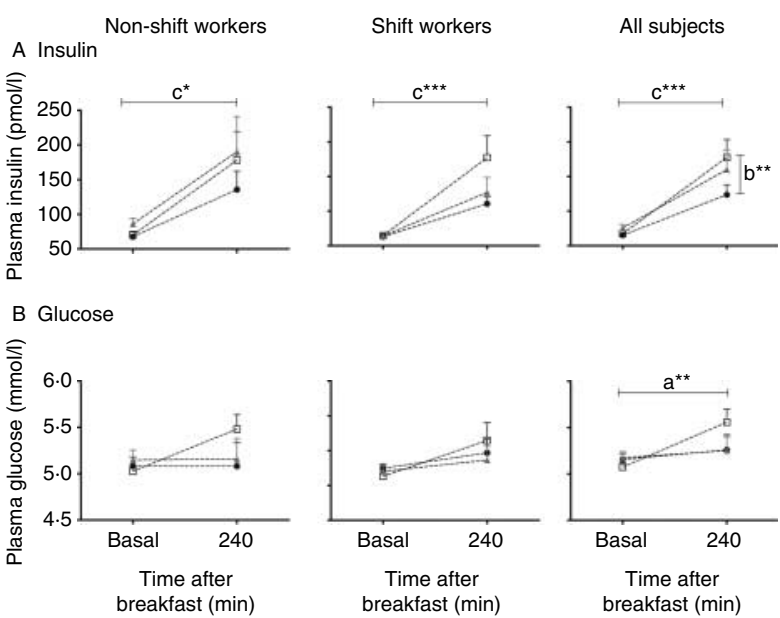

Figure 4 Plasma (A) insulin and (B) glucose (mean \pm S.E.M.) in the basal state and 240 min after the standard breakfast, following baseline sleep $(\bullet)$, sleep deprivation $(\square)$ and recovery sleep $(\Lambda)$ in the non-shift workers, shift workers and all the subjects. The letters represent the following comparisons: a, 240 min versus basal state following sleep deprivation; b, 240 min following sleep deprivation versus $240 \mathrm{~min}$ following baseline sleep; c, $240 \mathrm{~min}$ versus basal state on all the three days. ${ }^{*} P<0 \cdot 05 * * P<0 \cdot 01$ and $* * * P<0 \cdot 001$. $n=13$ for non-shift workers ( $n=12$ for insulin) and $n=11$ for shift workers.

The insulin IAUC was increased after recovery sleep (83 148 $\pm 8524 \mathrm{pmol} / \mathrm{l} \cdot \mathrm{min})$ than after sleep deprivation $(62644$ $\pm 5422 \mathrm{pmol} / \mathrm{l} \cdot \mathrm{min})$ and baseline sleep (59 $680 \pm 5205$ $\mathrm{pmol} / 1 \cdot \mathrm{min} ; P<0 \cdot 01)$. In addition, there was a trend for a day $\times$ group interaction for the net NEFA IAUC $\left(F_{2,44}=3, P=0 \cdot 061\right)$. No significant effects were observed for the TAG and glucose responses. When non-shift workers and shift workers were analysed separately, the effect of day on the insulin IAUC remained significant in the non-shift workers $\left(F_{1 \cdot 4,15}=7 \cdot 8, P<0 \cdot 01\right)$, with a larger insulin IAUC after recovery sleep $(96299 \pm 14174 \mathrm{pmol} / \mathrm{l} \cdot \mathrm{min})$ than after baseline sleep $(60923 \pm 8622 \mathrm{pmol} / \mathrm{l} \cdot \mathrm{min} ; \quad P<0 \cdot 01)$ and sleep deprivation $(64089 \pm 8323 \mathrm{pmol} / \mathrm{l} \cdot \mathrm{min} ; \quad P<0 \cdot 05)$. The day $X$ group interaction trend for the net NEFA IAUC appeared to be mainly due to an effect of day in the non-shift workers $\left(F_{1 \cdot 2,15}=3 \cdot 6, P=0 \cdot 068\right)$, with a smaller net NEFA IAUC after recovery sleep than after baseline sleep $(P<0 \cdot 05)$.

\section{Discussion}

This is the first study to report the effect of total sleep deprivation and recovery sleep per se on basal and postprandial metabolic and insulin responses to a standard breakfast. The responses of experienced shift workers with long-term exposure to shift work for 5 years or more were compared with those of the non-shift workers under well-controlled laboratory conditions.

Morning basal TAG levels were significantly lower after total sleep deprivation than after baseline and recovery sleep.
This finding is in agreement with the observations obtained using a protocol consisting of isocaloric meals being provided every $3 \mathrm{~h}$, which showed that 3-5 days of total sleep deprivation resulted in a significant decrease in the amplitude of the TAG rhythm and significantly lower TAG levels in the morning (Vondra et al. 1986). Ilan et al. (1992) also reported that $76-80 \mathrm{~h}$ total sleep deprivation resulted in a decrease in TAG levels, although food intake was ad libitum and body posture was not controlled. The lower TAG levels in the morning after total sleep deprivation may, in part, be due to higher energy expenditure while staying awake during the night, even though in the current study, the subjects were instructed to remain semi-recumbent throughout the night.
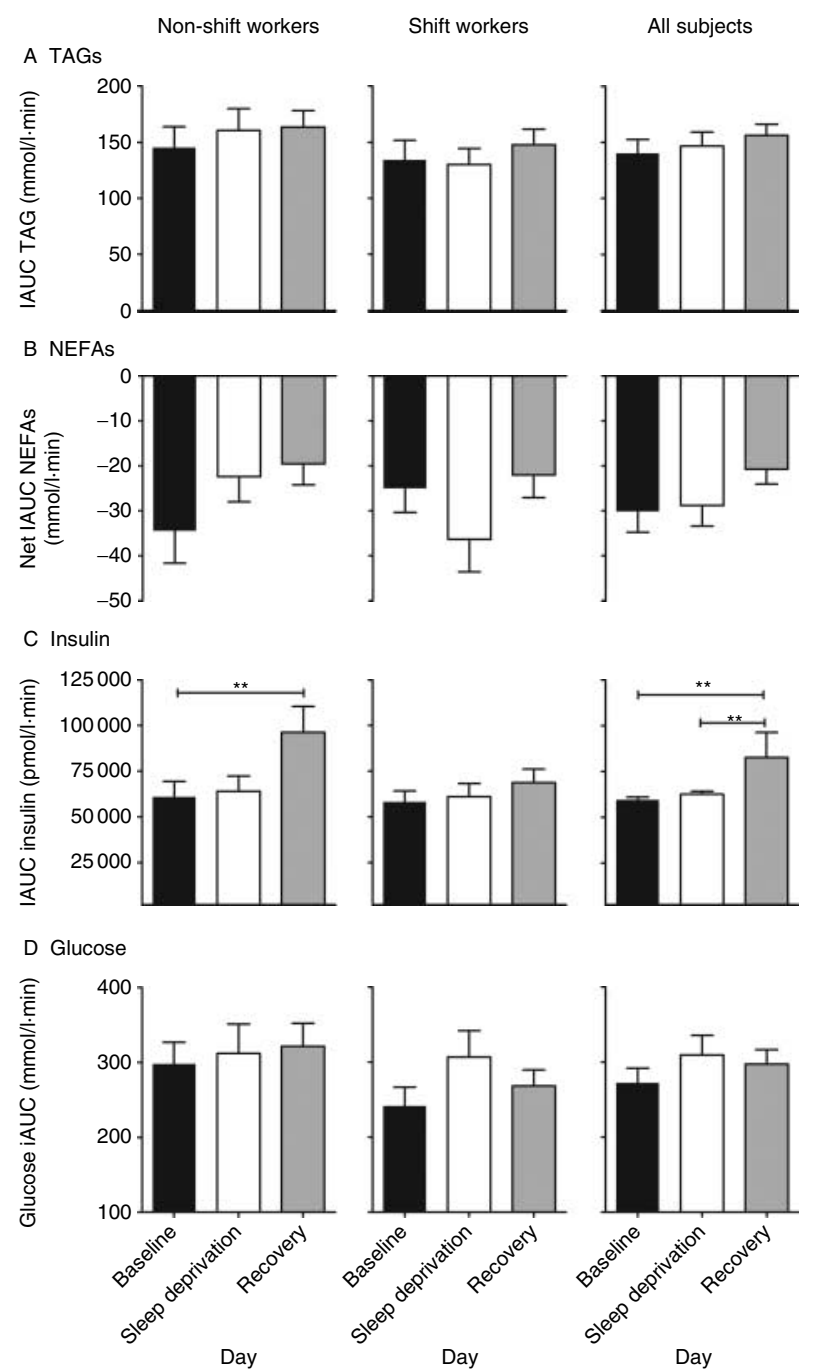

Figure 5 Incremental areas under the curve (IAUCs) for (A) TAGs, (B) NEFAs, (C) insulin and (D) glucose (mean \pm S.E.M.) after baseline sleep $(\square)$, sleep deprivation $(\square)$ and recovery sleep $(\square)$ in the nonshift workers, shift workers and all the subjects. ${ }^{* *} P<0 \cdot 01 . n=13$ for non-shift workers ( $n=12$ for insulin) and $n=11$ for shift workers. 
In agreement with this hypothesis, animal studies have reported lower/unaltered TAG levels after sleep deprivation, accompanied by weight loss despite higher food/calorie intake, indicating a higher turnover of nutrients during sleep deprivation (Everson \& Wehr 1993, Andersen et al. 2004, Martins et al. 2010). Alternatively, these observations could be due to impaired nutrient absorption. In agreement with the current finding, Nedeltcheva et al. (2009) did not observe any differences in fasting glucose and insulin levels between baseline sleep and partial sleep restriction. Other studies on partial sleep deprivation did not report the fasting glucose and insulin concentrations (Spiegel et al. 1999, Tasali et al. 2008).

Although energy utilisation may increase during sleep deprivation, the way the body deals with subsequent energy intake following a meal might be different. In the analysis done on all of the subjects, glucose levels $4 \mathrm{~h}$ after the standard breakfast did not return to basal levels after total sleep deprivation. In addition, insulin levels $4 \mathrm{~h}$ after the breakfast were significantly higher after sleep deprivation than after baseline sleep. This finding is in accordance with previous sleep deprivation studies (Spiegel et al. 1999, Tasali et al. 2008, Nedeltcheva et al. 2009). The slower glucose clearance despite increased insulin levels indicates insulin insensitivity (DeFronzo 1988, Reaven 2002). As glucose and insulin production and metabolism are tightly controlled by the autonomous nervous system (Iversen et al. 2000), it might be suggested, as has been done previously (Spiegel et al. 1999), that the insulin insensitivity after sleep deprivation may be due to an altered balance between the parasympathetic and sympathetic nervous systems. More specifically, it could be that the hypothalamus and, in particular, the wake-promoting factor orexin (Saper et al. 2005) plays a role in this process. Neurons from the hypothalamus project to the fat tissue, the liver and the pancreas (Kreier et al. 2006), and orexin has been shown to stimulate sympathetic neurons innervating these tissues (van den Top et al. 2003), which would lead to, for example, increased glucose mobilisation and altered insulin sensitivity (Shiuchi et al. 2009, Yi et al. 2009). Orexin has also been shown to increase in the cerebrospinal fluid of both squirrel monkeys and rats after sleep deprivation (Deboer $e t$ al. 2004, Zeitzer et al. 2007). Increased exposure to orexin during sustained wakefulness may therefore result in an overstimulation of the sympathetic nervous system and higher glucose mobilisation.

Significant effects of total sleep deprivation were observed on basal TAG levels and $4 \mathrm{~h}$ postprandial glucose and insulin levels. After a $4 \mathrm{~h}$ recovery nap followed by an $8 \mathrm{~h}$ overnight recovery sleep, the basal TAG levels were significantly higher than those after the sleep deprivation night in both the groups. In the non-shift workers, the average basal TAG level after recovery sleep was elevated above the levels reported to be associated with smaller and denser low-density lipoprotein production (TAG levels $>1.5 \mathrm{mmol} / \mathrm{l}$ ) which may increase the risk for CVD (Griffin et al. 1994). However, it has to be kept in mind that the basal samples in the current study were taken after a fasting period of $10.5 \mathrm{~h}$, and are thus not strictly considered fasting samples.

Basal NEFA levels were significantly lower after recovery sleep than after baseline sleep in the non-shift workers and in all the subjects. Basal insulin levels were significantly higher after recovery sleep than after baseline sleep and total sleep deprivation in the non-shift workers, suggestive of insulin insensitivity.

The overall TAG and insulin responses were higher and NEFA levels were lower after recovery sleep. The increased IAUC for insulin suggests that this increase after recovery sleep is likely to be independent of the change in basal levels. Similar glucose levels despite a significantly larger insulin response indicate insulin insensitivity. Moreover, this hyperinsulinaemic state would result in an enhanced hepatic conversion of NEFAs to TAGs and suppress lipid mobilisation by lipoprotein lipase, leading to hypertriglyceridaemia (DeFronzo 1988, Reaven 2002), which may explain the lower postprandial NEFA levels and the trend for a smaller net NEFA IAUC after recovery sleep than after baseline sleep. These results after recovery sleep are unexpected as most of the parameters in other studies (e.g. Spiegel et al. 1999, Mullington et al. 2003, van Leeuwen et al. 2009) show the largest alterations following sleep deprivation, and the parameters either remain changed after recovery sleep or start to return to basal levels. However, there is no satisfactory explanation as to why some parameters in this study would change after recovery sleep. This may be either a direct effect of recovery sleep or a delayed effect of sleep deprivation. Future studies including a longer recovery period or longer periods of (partial) sleep deprivation may help to clarify this issue.

Although there were no significant differences between nonshift workers and shift workers when they were assessed in the same ANOVA, separate analyses of non-shift workers and shift workers revealed some differences. In almost all the analyses, the effects of sleep deprivation and recovery sleep were more pronounced in the non-shift workers than in the shift workers. It could be speculated that the shift workers in this study appeared to be adapted to sleep deprivation. This observation might also be explained by other factors linked to the ability to cope with shift work and sleep deprivation, for example morningness-eveningness (Taillard et al. 1999, Mongrain et al. 2004, 2006) as assessed by the HÖ questionnaire, clock gene polymorphisms (Viola et al. 2007) and genetic variation in the adenosinergic system (Porkka-Heiskanen et al. 2003, Retey et al. 2005, 2006). The lack of major differences in the postprandial responses between the shift workers and non-shift workers may also be explained by the fact that the meal was given at the normal clock time. In previous studies reporting postprandial differences, meals were given at an abnormal clock time (Hampton et al. 1996, Ribeiro et al. 1998, Lund et al. 2001, Scheer et al. 2009), suggesting that the food intake at an inappropriate clock time may be a major contributor to the adverse effects of shift work.

One of the limitations of this study was the fact that the postprandial response was only measured for up to $4 \mathrm{~h}$ after 
the standard breakfast. Unfortunately, this time period could not be lengthened because lunch had to be included in the protocol before the scheduled nap. The peak of the TAG response was not observed, as it normally takes $\sim 9 \mathrm{~h}$ for TAGs to return to basal levels after a meal (Ribeiro et al. 1998, Lund et al. 2001, Sopowski et al. 2001). The decrease in TAGs observed after total sleep deprivation may thus not be a decrease but a delay in the TAG response; unfortunately, the protocol was unable to distinguish between these two. Future research should include longer sampling periods to assess how long it takes for TAGs, NEFAs, insulin and glucose to return to basal levels. Alternatively, subjects could be monitored after both breakfast and lunch as the postprandial hormone and metabolic responses may be additive if the time between the two meals is short.

In this study, an assumption that all measurements were taken at the same circadian phase for each subject was made. Circadian phase was predicted by habitual wake up time in contrast to using melatonin as a reliable marker of circadian phase (Klerman et al. 2002, Arendt 2003). Measurements may have thus been taken at slightly different circadian phases, although wake up time has been reported to be a good predictor of circadian phase when sleep and light exposure were controlled prior to the laboratory study (Burgess et al. 2003, Revell et al. 2005).

In conclusion, this is the first study to assess the basal and postprandial insulin and metabolic responses after total sleep deprivation and recovery sleep, and to compare nonshift workers and shift workers under controlled laboratory conditions. Significantly lower basal TAG levels after total sleep deprivation indicate higher energy expenditure during sleep deprivation, despite any increased physical activity. Postprandial TAG and insulin responses were larger after recovery sleep, suggestive of insulin insensitivity. These results might be explained by an altered balance between the parasympathetic and sympathetic nervous systems. The more pronounced effects of sleep deprivation and recovery sleep observed in the non-shift workers require further study.

\section{Declaration of interest}

The authors declare that there is no conflict of interest that could be perceived as prejudicing the impartiality of the research reported.

\section{Funding}

This work was supported by an EU Marie Curie Research Training Network grant (CT-2004-512362).

\section{Author contribution statement}

SMTW, SMH and DJS conceived and designed the experiments; SMTW, SMH and REF performed the experiments; SMTW analysed the data and SMTW, SMH and DJS wrote the paper.

\section{Acknowledgements}

We would like to thank the volunteers for participating in the study; students and staff at the University of Surrey for their help in carrying out the laboratory study; Dr Max Wong for assisting with the I-lab measurements and Mr Peter Williams for his statistical advice.

\section{References}

Akerstedt T 1998 Shift work and disturbed sleep/wakefulness. Sleep Medicine Reviews 2 117-128.

Akerstedt T 2003 Shift work and disturbed sleep/wakefulness. Occupational Medicine 53 89-94.

Andersen ML, Martins PJF, D'Almeida V, Santos RF, Bignotto M \& Tufik S 2004 Effects of paradoxical sleep deprivation on blood parameters associated with cardiovascular risk in aged rats. Experimental Gerontology 39 817-824.

Arendt J 2003 Importance and relevance of melatonin to human biological rhythms. Journal of Neuroendocrinology 15 427-431.

Barton J, Costa G, Smith L, Spelten E, Totterdell P \& Folkard S 1995 The standard shiftwork index: a battery of questionnaires for assessing shiftwork related problems. Work and Stress 9 3-30.

Beck AT \& Beamesderfer A 1974 Assessment of depression: the depression inventory. Modern Problems of Pharmacopsychiatry 7 151-169.

Beck AT, Rial WY \& Rickels K 1974 Short form of depression inventory: cross-validation. Psychological Reports 34 1184-1186.

Boggild H \& Knutsson A 1999 Shift work, risk factors and cardiovascular disease. Scandinavian Journal of Work, Environment \& Health 25 85-99.

Burgess HJ, Savic N, Sletten T, Roach G, Gilbert SS \& Dawson D 2003 The relationship between the dim light melatonin onset and sleep on a regular schedule in young healthy adults. Behavioral Sleep Medicine 1 102-114.

Buxton OM, L'Hermite-Baleriaux M, Turek FW \& van Cauter E 2000 Daytime naps in darkness phase shift the human circadian rhythms of melatonin and thyrotropin secretion. American Journal of Physiology. Regulatory, Integrative and Comparative Physiology 278 R373-R382.

Buysse DJ, Reynolds CF III, Monk TH, Berman SR \& Kupfer DJ 1989 The Pittsburgh Sleep Quality Index: a new instrument for psychiatric practice and research. Psychiatry Research 28 193-213.

De Bacquer D, Van Risseghem M, Clays E, Kittel F, De Backer G \& Braeckman L 2009 Rotating shift work and the metabolic syndrome: a prospective study. International Journal of Epidemiology 38 848-854 (dyn360).

Deboer T, Overeem S, Visser NA, Duindam H, Frolich M, Lammers GJ \& Meijer JH 2004 Convergence of circadian and sleep regulatory mechanisms on hypocretin-1. Neuroscience 129 727-732.

DeFronzo RA 1988 Lilly lecture 1987. The triumvirate: beta-cell, muscle, liver. A collusion responsible for NIDDM. Diabetes 37 667-687.

Ellingsen T, Bener A \& Gehani AA 2007 Study of shift work and risk of coronary events. Journal of the Royal Society for the Promotion of Health $\mathbf{1 2 7}$ 265-267.

Esquirol Y, Bongard V, Mabile L, Jonnier B, Soulat J-M \& Perret B 2009 Shift work and metabolic syndrome: respective impacts of job strain, physical activity, and dietary rhythms. Chronobiology International 26 544-559.

Everson CA \& Wehr TA 1993 Nutritional and metabolic adaptations to prolonged sleep deprivation in the rat. American Journal of Physiology 264 R376-R387.

Gangwisch JE, Heymsfield SB, Boden-Albala B, Buijs RM, Kreier F, Pickering TG, Rundle AG, Zammit GK \& Malaspina D 2006 Short sleep duration as a risk factor for hypertension: analyses of the first National Health and Nutrition Examination Survey. Hypertension 47 833-839.

Green CB, Takahashi JS \& Bass J 2008 The meter of metabolism. Cell 134 728-742.

Griffin BA, Freeman DJ, Tait GW, Thomson J, Caslake MJ, Packard CJ \& Shepherd J 1994 Role of plasma triglyceride in the regulation of plasma low density lipoprotein (LDL) subfractions: relative contribution of small, dense LDL to coronary heart disease risk. Atherosclerosis 106 241-253. 
Hampton SM, Morgan LM, Lawrence N, Anastasiadou T, Norris F, Deacon S, Ribeiro D \& Arendt J 1996 Postprandial hormone and metabolic responses in simulated shift work. Journal of Endocrinology 151 259-267.

Horne JA \& Östberg O 1976 A self-assessment questionnaire to determine morningness-eveningness in human circadian rhythms. International Journal of Chronobiology 4 97-110.

Ilan Y, Martinowitz G, Abramsky O, Glazer G \& Lavie P 1992 Prolonged sleep-deprivation induced disturbed liver functions serum lipid levels, and hyperphosphatemia. European Journal of Clinical Investigation 22 740-743.

Iversen S, Iversen L \& Saper C 2000 The autonomic nervous system and the hypothalamus. In Principles of Neural Science, edn 4, ch 49, pp 960-981 (international). Eds ER Kandel, JH Schwartz \& TM Jesell. New York: McGraw-Hill: Health Professions Division.

Johns MW 1991 A new method for measuring daytime sleepiness: the Epworth Sleepiness Scale. Sleep 14 540-545.

Johns MW 1992 Reliability and factor analysis of the Epworth Sleepiness Scale. Sleep 15 376-381.

Karlsson B, Knutsson A \& Lindahl B 2001 Is there an association between shift work and having a metabolic syndrome? Results from a population based study of 27,485 people Occupational and Environmental Medicine 58 747-752.

Karlsson BH, Knutsson AK, Lindahl BO \& Alfredsson LS 2003 Metabolic disturbances in male workers with rotating three-shift work. Results of the WOLF study. International Archives of Occupational and Environmental Health 76 424-430.

Kawachi I, Colditz GA, Stampfer MJ, Willett WC, Manson JE, Speizer FE \& Hennekens CH 1995 Prospective study of shift work and risk of coronary heart disease in women. Circulation 92 3178-3182.

Klerman EB, Gershengorn HB, Duffy JF \& Kronauer RE 2002 Comparisons of the variability of three markers of the human circadian pacemaker. Journal of Biological Rhythms 17 181-193.

Knutsson A \& Boggild H 2000 Shiftwork and cardiovascular disease: review of disease mechanisms. Reviews on Environmental Health 15 359-372.

Knutsson A, Akerstedt T, Jonsson BG \& Orth-Gomer K 1986 Increased risk of ischaemic heart disease in shift workers. Lancet 2 89-92.

Kreier F, Kap YS, Mettenleiter TC, van Heijningen C, van der Vliet J, Kalsbeek A, Sauerwein HP, Fliers E, Romijn JA \& Buijs RM 2006 Tracing from fat tissue, liver, and pancreas: a neuroanatomical framework for the role of the brain in type 2 diabetes. Endocrinology 147 1140-1147.

van Leeuwen WMA, Lehto M, Karisola P, Lindholm H, Luukkonen R, Sallinen M, Härmä M, Porkka-Heiskanen T \& Alenius H 2009 Sleep restriction increases the risk of developing cardiovascular diseases by augmenting proinflammatory responses through IL-17 and CRP. PLoS ONE 4 e4589.

Lockley SW, Skene DJ \& Arendt J 1999 Comparison between subjective and actigraphic measurement of sleep and sleep rhythms. Journal of Sleep Research 8 175-183.

Lund J, Arendt J, Hampton SM, English J \& Morgan LM 2001 Postprandial hormone and metabolic responses amongst shift workers in Antarctica. Journal of Endocrinology 171 557-564.

Martins PJ, Marques MS, Tufik S \& D’Almeida V 2010 Orexin activation precedes increased NPY expression, hyperphagia, and metabolic changes in response to sleep deprivation. American Journal of Physiology. Endocrinology and Metabolism 298 E726-E734.

Mongrain V, Lavoie S, Selmaoui B, Paquet J \& Dumont M 2004 Phase relationships between sleep-wake cycle and underlying circadian rhythms in morningness-eveningness. Journal of Biological Rhythms 19 248-257.

Mongrain V, Carrier J \& Dumont M 2006 Circadian and homeostatic sleep regulation in morningness-eveningness. Journal of Sleep Research 15 $162-166$.

Monteleone P, Tortorella A, Docimo L, Maldonato MN, Canestrelli B, De Luca L \& Maj M 2008 Investigation of 3111T/C polymorphism of the CLOCK gene in obese individuals with or without binge eating disorder: association with higher body mass index. Neuroscience Letters $\mathbf{4 3 5}$ 30-33.

Mullington JM, Chan JL, Van Dongen HP, Szuba MP, Samaras J, Price NJ, Meier-Ewert HK, Dinges DF \& Mantzoros CS 2003 Sleep loss reduces diurnal rhythm amplitude of leptin in healthy men. Journal of Neuroendocrinology 15 851-854.
Nedeltcheva AV, Kessler L, Imperial J \& Penev PD 2009 Exposure to recurrent sleep restriction in the setting of high caloric intake and physical inactivity results in increased insulin resistance and reduced glucose tolerance. Journal of Clinical Endocrinology and Metabolism 94 3242-3250.

Pilcher JJ, Lambert BJ \& Huffcutt AI 2000 Differential effects of permanent and rotating shifts on self-report sleep length: a meta-analytic review. Sleep 23 155-163.

Porkka-Heiskanen T, Kalinchuk A, Alanko L, Urrila A \& Stenberg D 2003 Adenosine, energy metabolism, and sleep. Scientific World Journal 3 790-798.

Reaven GM 2002 Control of blood glucose and its disturbance: insulin resistance. In Comprehensive Clinical Endocrinology, edn 3, pp 291-301. Eds GM Besser \& MO Thorner. Edinburgh: Mosby.

Retey JV, Adam M, Honegger E, Khatami R, Luhmann UF, Jung HH, Berger W \& Landolt HP 2005 A functional genetic variation of adenosine deaminase affects the duration and intensity of deep sleep in humans. PNAS 102 15676-15681.

Retey JV, Adam M, Gottselig JM, Khatami R, Durr R, Achermann P \& Landolt HP 2006 Adenosinergic mechanisms contribute to individual differences in sleep deprivation-induced changes in neurobehavioral function and brain rhythmic activity. Journal of Neuroscience $\mathbf{2 6}$ 10472-10479.

Revell VL, Kim H, Tseng CY, Crowley SJ \& Eastman CI 2005 Circadian phase determined from melatonin profiles is reproducible after $1 \mathrm{wk}$ in subjects who sleep later on weekends. Journal of Pineal Research 39 195-200.

Ribeiro DC, Hampton SM, Morgan L, Deacon S \& Arendt J 1998 Altered postprandial hormone and metabolic responses in a simulated shift work environment. Journal of Endocrinology 158 305-310.

Sallinen M, Härmä M, Mutanen P, Ranta R, Virkkala J \& Muller K 2003 Sleep-wake rhythm in an irregular shift system. Journal of Sleep Research $\mathbf{1 2}$ 103-112.

Saper CB, Scammell TE \& Lu J 2005 Hypothalamic regulation of sleep and circadian rhythms. Nature 437 1257-1263.

Scheer FAJL, Hilton MF, Mantzoros CS \& Shea SA 2009 Adverse metabolic and cardiovascular consequences of circadian misalignment. PNAS 106 4453-4458.

Schernhammer ES, Laden F, Speizer FE, Willett WC, Hunter DJ, Kawachi I \& Colditz GA 2001 Rotating night shifts and risk of breast cancer in women participating in the nurses' health study. Journal of the National Cancer Institute 93 1563-1568.

Scott EM, Carter AM \& Grant PJ 2008 Association between polymorphisms in the Clock gene, obesity and the metabolic syndrome in man. International Journal of Obesity 32 658-662.

Shiuchi T, Haque MS, Okamoto S, Inoue T, Kageyama H, Lee S, Toda C, Suzuki A, Bachman ES, Kim YB et al. 2009 Hypothalamic orexin stimulates feeding-associated glucose utilization in skeletal muscle via sympathetic nervous system. Cell Metabolism 10 466-480.

Simon C, Weibel L \& Brandenberger G 2000 Twenty-four-hour rhythms of plasma glucose and insulin secretion rate in regular night workers. American Journal of Physiology. Endocrinology and Metabolism 278 E413-E420.

Sookoian S, Gemma C, Fernandez Gianotti T, Burgueno A, Alvarez A, Gonzalez CD \& Pirola CJ 2007 Effects of rotating shift work on biomarkers of metabolic syndrome and inflammation. Journal of Internal Medicine $\mathbf{2 6 1}$ 285-292.

Sookoian S, Gemma C, Gianotti TF, Burgueno A, Castano G \& Pirola CJ 2008 Genetic variants of Clock transcription factor are associated with individual susceptibility to obesity. American Journal of Clinical Nutrition $\mathbf{8 7}$ 1606-1615.

Sopowski MJ, Hampton SM, Ribeiro DCO, Morgan L \& Arendt J 2001 Postprandial triacylglycerol responses in simulated night and day shift: gender differences. Journal of Biological Rhythms 16 272-276.

Spiegel K, Leproult R \& Van Cauter E 1999 Impact of sleep debt on metabolic and endocrine function. Lancet 354 1435-1439.

Taheri S, Lin L, Austin D, Young T \& Mignot E 2004 Short sleep duration is associated with reduced leptin, elevated ghrelin, and increased body mass index. PLoS Medicine 1 e62.

Taillard J, Philip P \& Bioulac B 1999 Morningness/eveningness and the need for sleep. Journal of Sleep Research 8 291-295. 
Tasali E, Leproult R, Ehrmann DA \& Van Cauter E 2008 Slow-wave sleep and the risk of type 2 diabetes in humans. PNAS $\mathbf{1 0 5}$ 1044-1049.

van den Top M, Nolan MF, Lee K, Richardson PJ, Buijs RM, Davies CH \& Spanswick D 2003 Orexins induce increased excitability and synchronisation of rat sympathetic preganglionic neurones. Journal of Physiology 549 809-821.

Viola AU, Archer SN, James LM, Groeger JA, Lo JC, Skene DJ, von Schantz M \& Dijk DJ 2007 PER3 polymorphism predicts sleep structure and waking performance. Current Biology 17 613-618.

Viola AU, James LM, Archer SN \& Dijk DJ 2008 PER3 polymorphism and cardiac autonomic control: effects of sleep debt and circadian phase. American Journal of Physiology. Heart and Circulatory Physiology 295 H2156-H2163.

Vondra K, Brodan V, Dobiasova M, Vitek V \& Kopecka J 1986 Effect of sleep deprivation on cholesterol metabolism and triglyceridaemia in male volunteers. European Journal of Applied Physiology and Occupational Physiology 55 83-87.
Woon PY, Kaisaki PJ, Braganca J, Bihoreau MT, Levy JC, Farrall M \& Gauguier D 2007 Aryl hydrocarbon receptor nuclear translocator-like (BMAL1) is associated with susceptibility to hypertension and type 2 diabetes. PNAS 104 14412-14417.

Yi CX, Serlie MJ, Ackermans MT, Foppen E, Buijs RM, Sauerwein HP, Fliers E \& Kalsbeek A 2009 A major role for perifornical orexin neurons in the control of glucose metabolism in rats. Diabetes $\mathbf{5 8} 1998-2005$.

Zeitzer JM, Buckmaster CL, Lyons DM \& Mignot E 2007 Increasing length of wakefulness and modulation of hypocretin- 1 in the wake-consolidated squirrel monkey. American Journal of Physiology. Regulatory, Integrative and Comparative Physiology 293 R1736-R1742 (00460.02007).

Received in final form 25 April 2010

Accepted 17 May 2010

Made available online as an Accepted Preprint 17 May 2010 